\title{
Evaluation of Pyloric Stenosis Management, Laparoscopic versus Open Pyloromyotomy
}

\author{
Awath Fahim Alsulami ${ }^{1}$, Abdulrahman Abdullah Alzahrani ${ }^{1}$, Ahmed Bakr Ibrahim ${ }^{2}, \quad$ Ali \\ Abdulla Almazeedi ${ }^{3}$, Abdullah Saud Alfaraj ${ }^{3}$, Asma Mutni Al-Mutairi ${ }^{4}$, Razan Mohammad S \\ Almuallad $^{5}$, Maram Mudhhi Alabdali ${ }^{5}$, Hadeel Taha Alsaadi ${ }^{5}$, Bodoor Salmi Almotairi ${ }^{6}$ \\ 1- Umm Al- Qura University, 2- King Saud bin Abdulaziz University, 3- Mansoura University, \\ 4- Al-Qassim University, 5- Ibn Sina National College, 6- Taibah University
}

\begin{abstract}
Background: Hypertrophic pyloric stenosis (HPS) is associated with gastric outlet obstruction that occurs as a result of pylorus muscular layers hypertrophy. HPS is considered as the most common cause of vomiting in infancy that requires surgical intervention. Despite advances in neonatal and surgical care, still there is a debate between the pediatric surgeons about the approach that can provide better outcomes for the patients. Objective: In our paper, we aimed to review the recent randomized clinical trials and reviews that compared between laparoscopic and open pyloromyotomy to assess their outcomes, merits and pitfall of each. Methods: PubMed database was used for articles selection, and the following keys used in the mesh ("Hypertrophic Pyloric Stenosis /management"[Mesh] OR "। Hypertrophic Pyloric Stenosis /outcomes"[Mesh]) AND ("Mortality/Morbidity"[Mesh]). A total of 12 studies were enrolled into our review according to our inclusion and exclusion criteria. Conclusion: We found that overall Laparoscopic pyloromyotomy procedures were as safe and effective as Open pyloromyotomy procedures for infants with hypertrophic pyloric stenosis. However, there was a trend in the LP group towards shorter time, especially with regard to the full time to feeds, length of stay after surgery, operating time. We think that our findings justify the continued use of laparoscopic pyloromyotomy for the management of infantile hypertrophic pyloric stenosis, and recommend its use in centers with appropriate laparoscopic experience.
\end{abstract}

Key words: pyloric stenosis, management, laparoscopic pyloromyotomy, open pyloromyotomy.

\section{INTRODUCTION}

Hypertrophic pyloric stenosis (HPS) is associated with gastric outlet obstruction that occurs as a result of pylorus muscular layers hypertrophy ${ }^{[1]}$. HPS is considered as the most common cause of vomiting in infancy that requires surgical intervention. This condition was described in 1888 for the first time by Hirschprung ${ }^{[2]}$. Since that time its incidence has been increasing. Worldwide the incidence of HPS is approximately 1-3 per 1,000 live births, although rates and trends vary markedly from region to region ${ }^{[3]}$. Ghazwany et al. ${ }^{[4]}$ estimated the incidence rate in Saudi Arabia to be $1.4 / 10000$ live births ${ }^{[3]}$. HPS is more common in males than females ( $4: 1$ to $6: 1$ ), and more frequent in preterm infant than full term [5].

Until now the etiologies that stand behind the development of HPS is still unclear. Several theories have been postulated, but none has been proven. The recent literatures found that HPS is multifactorial, involving genetic predisposition and environmental factors. Neonatal hypergastrinemia and gastric hyperacidity may play a role ${ }^{[4]}$. Premature birth may play a role; Ghazwany et al. ${ }^{[4]}$ found that the incidence of 2.99/1000 occur in preterm infants compared to $2.25 / 1000$ in term infants. Examination of the pylorus itself has revealed deficiency or abnormality in the nerve cell fiber, decreased levels of nitric oxide synthase, and increased levels of growth factors (insulin-like growth factor and platelet derived growth factor), which, individually or in combination, may result in failure of pyloric relaxation and/or muscle hypertrophy ${ }^{[5]}$.

The gold standard management for HPS is surgical pyloromyotomy, which used to be done via open right upper quadrant or supraumbilical incision. However, with the recent advances in the medical field, a laparoscopic technique for pyloromyotomy was introduced in 1991, and both techniques are now widely utilized.

Despite advances in neonatal and surgical care, still there is a debate between the pediatric surgeons about the approach that can provide better outcomes for the patients. In our paper we reviewed the recent randomized clinical trials and reviews that compared between 
laparoscopic and open pyloromyotomy to assess their outcomes, merits and pitfall of each.

\section{METHODOLOGY}

Sample

PubMed was chosen as the search database for the articles selection, because it is one of the major research databases within the suite of resources that have been developed by the National Center for Biotechnology Information (NCBI). The following keys used for the Mesh ("Hypertrophic Pyloric Stenosis /management"[Mesh] OR "\ Hypertrophic Pyloric Stenosis /outcomes"[Mesh]) AND ("Mortality/Morbidity"[Mesh]). Inclusion criteria, the articles selected were based on the relevance to the project which should include one of the following topics, \{ Hypertrophic pyloric stenosis, HPS Management, HPS Outcomes, laparoscopic and open pyloromyotomy \& Morbidity\}. Exclusion criteria, all other articles which didn't have one of these topics as their primary end point, or repeated studies.

\section{Analysis}

No software was used, The data extracted based on specific form that contain (Title of the study, name of the author, Objective, Summary, Results, and Outcomes), these data were reviewed by the group members to assess different management plans of $\mathrm{CDH}$, and the outcomes related. Double revision of each member's outcomes was applied to ensure the validity and minimize errors.

\section{RESULTS}

We enrolled a total 12 studies according to our inclusion, and exclusion criteria described above. 8 of them were a retrospective studies, and the remaining were a randomized clinical trials. All of the included study discussed various aspects of pyloric stenosis management and outcomes. The studies characteristics are shown in Table 1.

\section{DISCUSSION}

During infancy, hypertrophic pyloric stenosis (HPS) is the most cause of vomiting that requires a surgical intervention. This condition was described in 1888 for the first time by
Hirschprung ${ }^{[2]}$. Since that time its incidence has been increasing. Worldwide the incidence of HPS is approximately 1-3 per 1,000 live births, although rates and trends vary markedly from region to region ${ }^{[3]}$. Al-Ghazwany et al. ${ }^{[4]}$ estimated the incidence rate in Saudi Arabia to be 1.4/10 000 live births ${ }^{3}$. HPS in general occur more commonly in white males which represent a gender and race predilection. In addition, HPS occurrence has a familial presentation in which $15 \%$ of male offspring from an affected mother developing the disease.

The etiologies that lead to development of HPS are still elusive. Various theories have been mentioned, but none has been proven. According to the recent literatures HPS is a multifactorial, involving genetic predisposition and environmental factors. Neonatal hypergastrinemia and gastric hyperacidity may play a role ${ }^{[9]}$. Also, they found that premature birth may play a role in HPS development.

Infant with HPS almost all of them present between 3 weeks and 3 months of age and has developed progressively worsening nonbilious vomiting. HPS can occur in premature infants as well. A physician should take in mind during the history taking to ask about the pattern of vomiting because it plays a major role during the diagnosis process. In HPS vomiting is postprandial and projectile in nature, which occur as a result of progressive and forceful contraction of gastric musculature to move the gastric content through the obstructed pylorus. As the condition progress without any intervention blood stained vomiting might be seen as a result of gastritis that occur as a result of repetitive emesis. The infant with HPS is always hungry, and ask for food after each vomiting.

As a result of repetitive vomiting, the infant will fail to thrive and present with poor nutritional status. Also, infants with HPS as a result of poor nutrition are at risk of dehydration development. With the continuous vomiting, the gastric secretions are lost, which lead to development of hypokalemic, hypochloremic metabolic alkalosis that can progress to paradoxical aciduria as a result of the renal response to volume contraction and increasing alkalosis.

Table (1): Included studies details. 


\begin{tabular}{|c|c|c|c|c|}
\hline Carrington et al. ${ }^{[7]}$ & RCT & $\begin{array}{l}\text { Cost-effectiveness of laparoscopic } \\
\text { versus open pyloromyotomy }\end{array}$ & $\begin{array}{l}\text { LP is a cost-effective alternative to OP as it delivers } \\
\text { improved clinical outcome at a lower price. }\end{array}$ & 7 \\
\hline $\begin{array}{l}\text { Siddiqui } \text { et al. }{ }^{\text {[9] }} \\
\text { (2012) }\end{array}$ & RCT & $\begin{array}{l}\text { To compare open with laparoscopic } \\
\text { pyloromyotomies for HPS with } \\
\text { assessment of parent satisfaction with } \\
\text { cosmetic results. }\end{array}$ & $\begin{array}{l}\text { There was no difference in operating time, hospital stay, } \\
\text { or refeeding patterns between open and laparoscopic } \\
\text { pyloromyotomy. The complication rates were similar } \\
\text { between the } 2 \text { methods. However, long-term cosmetic } \\
\text { results were significantly superior in the laparoscopic } \\
\text { group. }\end{array}$ & 9 \\
\hline Lange et al. ${ }^{[11]}$ & $\begin{array}{l}\text { Retrospective } \\
\text { Cohort study }\end{array}$ & $\begin{array}{l}\text { To clarify whether the laparoscopic } \\
\text { procedure has any advantages when } \\
\text { compared to the open approach. }\end{array}$ & $\begin{array}{l}\text { There was no difference in the complication rate as } \\
\text { compared to the open procedure. The recovery time was } \\
\text { shorter in the laparoscopic group. A superiority of the } \\
\text { laparoscopic pyloromyotomy over the open procedure is } \\
\text { suggested by the ascertained data. }\end{array}$ & 11 \\
\hline Vegunta et al. ${ }^{[12]}$ & $\begin{array}{l}\text { Retrospective } \\
\text { Cohort study }\end{array}$ & $\begin{array}{l}\text { Our hypothesis was that, with } \\
\text { experience, the outcomes of LP will } \\
\text { equal or surpass that of open } \\
\text { pyloromyotomy }(\mathrm{OP}) \text {. }\end{array}$ & $\begin{array}{l}\text { We are able to demonstrate that, with experience, one } \\
\text { can expect progressive improvement in the outcomes } \\
\text { following LP in infants. Our surgery duration and } \\
\text { complications in the last } 65 \text { cases are better than most } \\
\text { published results for OP or LP. }\end{array}$ & 12 \\
\hline Binet et al. ${ }^{[15]}$ & $\begin{array}{l}\text { Retrospective } \\
\text { Cohort study }\end{array}$ & $\begin{array}{l}\text { Make a review of all our LP } \\
\text { procedures with an objective } \\
\text { evaluation according to the literature. }\end{array}$ & $\begin{array}{l}\text { LP procedure appeared to be as quick as the open } \\
\text { procedure. LP procedure causes little pain during the } \\
\text { postoperative period. No wound complications were } \\
\text { registered. }\end{array}$ & 15 \\
\hline Costanzo et al. ${ }^{[16]}$ & $\begin{array}{l}\text { Retrospective } \\
\text { Cohort study }\end{array}$ & $\begin{array}{l}\text { To compare postoperative } \\
\text { complications and length of stay for } \\
\text { infants undergoing laparoscopic } \\
\text { versus open pyloromyotomy. }\end{array}$ & $\begin{array}{l}\text { We have demonstrated that post-operative outcomes } \\
\text { after laparoscopic pyloromyotomy are equivalent or } \\
\text { superior to an open approach. The minimally invasive } \\
\text { approach to pyloromyotomy is a safe and feasible option } \\
\text { in the treatment of HPS in infants. }\end{array}$ & 16 \\
\hline
\end{tabular}

A physician can suspect HPS by a good history taking and physical examination. During the examination, the physician may palpate a "olive" (the enlarged pylorus) in the epigastrium, usually just to the right of midline. The pylorus is mobile in its superior/inferior direction and is palpated more easily with the stomach empty (after emesis) and the child quiet. Additionally, physicians can use abdominal ultrasound as a diagnostic test to help them in HBS diagnosis. Generally accepted guidelines for the diagnosis of HPS by ultrasound include a wall thickness of $4 \mathrm{~mm}$ and a pyloric channel length of at least $16 \mathrm{~mm}$.

The gold standard management for HPS is surgical pyloromyotomy which can be done via open or laparoscopic procedure. In our paper we reviewed the recent randomized clinical 
trials and reviews that compared between laparoscopic and open pyloromyotomy to assess their outcomes, merits and pitfall of each.

Open pyloromyotomy (OP), was used for the first time in 1903 by Dent. Subsequently, different surgeons used the extramucosal pyloroplasty by dividing the pyloric muscle transversally and leaving the mucosa intact. In 1911 Ramstedt was the first one to divide the muscle longitudinally. Ramstedt procedure was done through a transverse right upper quadrant abdominal laparotomy. Later on, in 1986, Tan and Bianchi first described 40 children who underwent pyloromyotomy via a circumumbilical incision. According to the literatures none of these techniques seems to be superior to the other one, except that circumumbilical incision might have a better cosmetic outcomes.

The first laparoscopic pyloromyotomy (LP), was done for the first time in 1990. Since then, many centers have used this technique expecting better cosmetic results and faster recovery from surgery. LP is done by using a 3 $\mathrm{mm}$ or $5 \mathrm{~mm}$ port in the umbilical fold to hold a telescope. Then a capnoperitoneum is established. After that, another two incisions are done in the upper abdomen to insert a $3 \mathrm{~mm}$ instruments without trocars. Finally, the hypertrophic muscle fiber are spread with an endoscopic spreader in a longitudinal way.

Hall et al. ${ }^{[6]}$. discussed the various outcomes differences between (LP) and (OP), they found that both had low risk for the management of pyloric stenosis. However, laparoscopy is considered superior over open pyloromyotomy due to short time procedure, full enteral feed was tolerated and early discharge. Carrington et al. [7] studied the financial aspects of laparoscopic versus open pyloromyotomy, and found that LP is a cost-effective compared to $\mathrm{OP}$ as it delivers improved clinical outcome at a lower price. Peter et al. ${ }^{[8]}$ evaluated the potential cosmetic benefits of LP over OP; they found that surgical scars are almost always identifiable with OP while the surgical scars associated with LP approach invisibility to the observer, appearing similar to patients with no prior abdominal operation. Ali et al. ${ }^{[10]}$ found the LP is as safe as OP and have additional benefits of short LOS and cosmetics. Lange $\boldsymbol{e t}$ al. ${ }^{[11]}$ mentioned that there is no difference in complications between two procedures and the LP had shorter recovery time. Vegunta et al. ${ }^{[12]}$ mentioned that LP can provide better outcomes for infant with HPS especially if it was done by an experienced surgeon. Mahida et al. ${ }^{[14]}$, determined the impact of laparoscopic versus open pyloromyotomy on postoperative length of stay (LOS), he found OP is independently associated with higher likelihood of a prolonged postoperative LOS. Binet et al. ${ }^{[15]}$ found the LP operation time same as OP and LP postoperative pain is little. Costanzo et al. ${ }^{[16]}$ compared between the two procedures in postoperative complication and length of hospital stay. They found that postoperative complications of LP is the same or superior to $\mathrm{OP}$, and the minimal invasive approach to pyloromyotomy is safe and practical option for HPS treatment. Kethman et al. ${ }^{[17]}$ agreed with Costanzo et al. ${ }^{[16]}$ in which LP associated is with lower complications rate compared to OP and it's safer, effective procedures for HPS in centers capable of minimally invasive surgery. Although the number of studies on which our conclusion based is small, we found that overall LP procedures were as safe and effective as OP procedures for infants undergoing pyloromyotomy. However, there was a trend in the LP group towards shorter time, especially with regard to the full time to feeds, length of stay after surgery, operating time, costeffectiveness, decreased analgesia requirements, and improved parental cosmetic satisfaction. Overall, our findings suggest that, although both procedures are safe, laparoscopy has several advantages over open pyloromyotomy, with almost same postoperative complications. We think that our findings justify the continued use of laparoscopic pyloromyotomy for the management of infantile hypertrophic pyloric stenosis, and recommend its use in centers with appropriate laparoscopic experience.

\section{REFERENCES}

1. Maheshwai N (2007): Are young infants treated with erythromycin at risk for developing hypertrophic pyloric stenosis . Arch Dis Child, 2 (3) : $271-273$

2. Mullassery D, Perry D, Goyal A et al. (2008): Surgical practice for infantile hypertrophic pyloric stenosis in the United Kingdom and Ireland-a survey of members of the British Association of Paediatric Surgeons. J Pediatr Surg., 43:1227-1229. 
3. Grant GA and McAleer JJ (1984): Incidence of infantile hypertrophicpyloric stenosis. Lancet, 1:1177-1183

4. Al-Ghazwany S (2012): Infantile hypertrophic pyloric stenosis: a single institution's experience. Annals of Pediatric Surgery, 8:39-41

5. Rogers IM (1997): The enigma of pyloric stenosis. Some thoughts on the aetiology. Acta Paediatr., 86:6-13.

6. Hall NJ, Pacilli M, Eaton S et al. (2009): Recovery after open versus laparoscopic pyloromyotomy for pyloric stenosis: a double-blind multicentre randomised controlled trial. Lancet, 31;373(9661):3908.

7. Carrington EV, Hall NJ, Pacilli M et al. (2012): Cost-effectiveness of laparoscopic versus open pyloromyotomy. J Surg Res., 178(1):315-20.

8. Peter SD, Acher CW, Shah SR et al. (2016): Parental and Volunteer Perception of Pyloromyotomy Scars: Comparing Laparoscopic, Open, and Nonsurgical Volunteers. J Laparoendosc Adv Surg Tech A., 26(4):305-308.

9. Siddiqui S, Heidel RE, Angel CA et al. (2012): Pyloromyotomy: randomized control trial of laparoscopic vs open technique. J Pediatr Surg., 47(1):93-98.

10. Ali A, Tripuraneni G, Velmurugan $S$ et al. (2008): Laparoscopic pyloromyotomy is both safe and effective in a district hospital. Surg Endosc., 22(1):151-3.
11. Lange R, Rey M \& DomÍnguez E (2008): Open vs. laparoscopic pyloromyotomy - a retrospective analysis. Minimally Invasive Therapy, 17:5; 313-317.

12. Vegunta RK, Woodland JH, Rawlings AL et al. (2007): Practice makes perfect: progressive improvement of laparoscopic pyloromyotomy results, with experience. $\mathbf{J}$ Laparoendosc Adv Surg Tech A., 18(1):152-156.

13. Lemoine $C$, Paris $C$, Morris $M$ et al. (2011): Open transumbilical pyloromyotomy: is it more painful than the laparoscopic approach? J Pediatr Surg., 46(5):870-3.

14. Mahida JB (2016): Laparoscopic pyloromyotomy decreases postoperative length of stay in children with hypertrophic pyloric stenosis, J Pediatr Surg., 51(9): 1436 - 1439.

15. Binet A, Klipfel $C$, Meignan $P$ et al. (2018): Laparoscopic pyloromyotomy for hypertrophic pyloric stenosis: a survey of 407 children. Pediatr Surg Int., 34(4):421426.

16. Costanzo CM, Vinocur $C$ and Berman $L$ (2018): Postoperative outcomes of open versus laparoscopic pyloromyotomy for hypertrophic pyloric stenosis. J Surg Res., 224:240-244.

17. Kethman WC, Harris AH, Hawn MT et al. (2018): Trends and surgical outcomes of laparoscopic versus open pyloromyotomy. Surg Endosc., 32(7):3380-3385. 